\title{
Mesostructuring layered materials: self-supported mesoporous layered double hydroxide nanotubes $\uparrow$
}

Received 00th January 20xx, Accepted 00th January 20xx DOI: $10.1039 / x 0 x \times 00000 x$

\author{
Alysson F. Morais, ${ }^{a}$ Dimy Nanclares, ${ }^{a}$ Ivan G.N. Silva, ${ }^{a}$ Alfredo Duarte, ${ }^{b}$ Fernando A. Garcia, ${ }^{a}$ Eric \\ Breynaert $^{\mathrm{c}}$ and Danilo Mustafa*
}

Synthesis of layered materials exhibiting hierarchical porosity remains challenging, but nevertheless worthwhile because it turns such solids into functional materials with high specific surface area. Using a soft-templating strategy in combination with the incorporation of 8-fold coordinated $\mathrm{Eu}^{3+}$, self-assembly of selfsupported layered double hydroxide (LDH) nanotubes has been achieved. Heteromorphic equimolar substitution of $\mathrm{Al}^{3+}$ by 8 -fold coordinated $\mathrm{Eu}^{3+}$ in $\mathrm{Zn}^{2+} / \mathrm{Al}^{3+} \mathrm{LDH}$ solids intercalated with 1,3,5benzenetricarboxylate anions (BTC) assists precipitation of the double hydroxide layers onto the convex surface of Pluronic ${ }^{\circledR}$ P-123 worm-like micelles, yielding multilayer cylinders of BTCintercalated LDHs. Removal of the micellar template is easily achieved by liquid extraction with methanol, yielding a network of interconnected, well-defined, self-supported, multi-walled, hollow cylindrical nanotubes. Removal of $\mathrm{Eu}^{3+}$ from the synthesis disables formation of the nanotubular morphology, but still yields LDHs containing a network of embedded mesopores, resulting in a specific surface area that is $\mathbf{5}$-fold higher as compared to standard LDHs.

\section{Introduction}

The interest in the controlled fabrication of porous materials is fueled by the score of commercial applications demonstrated for these matrices, examples ranging from catalysis, separation science and chromatography to gas storage and sensing ${ }^{1-3}$. Layered double hydroxides (LDH) are intrinsically microporous materials formed by stacks of hydrated anion planes $\left(\mathrm{A}^{\mathrm{n}-} \cdot \mathrm{yH}_{2} \mathrm{O}\right)$ alternating with positively charged, mixed metal

\footnotetext{
a. Instituto de Física da Universidade de São Paulo, 05508-090, São Paulo, SP, Brazil b.E-mail:dmustafa@if.usp.br.

c. Instituto de Química da Universidade de São Paulo, 05508-000, São Paulo, SP, Brazil.

d. Center for Surface Chemistry and Catalysis, KU Leuven, B-3001, Leuven, Belgium.

$\dagger$ Electronic Supplementary Information (ESI) available: Synthesis and characterization of new compounds, chemical composition, peak positions of X-ray diffraction features, details of EXAFS data analysis, electron micrographs, photoluminescence spectroscopy and thermogravimetric curves. See DOI: $10.1039 / x 0 x x 00000 x$
}

hydroxide layers with chemical formula $\left[\mathrm{M}_{1-\mathrm{x}}^{\mathrm{II}} \mathrm{M}_{\mathrm{x}}^{\mathrm{III}}(\mathrm{OH})_{2}\right]^{x+}$, where $\mathrm{M}^{\prime \prime}$ and $\mathrm{M}^{\prime \prime \prime}$ are, respectively, di- and trivalent metals ${ }^{4,5}$. Anions and water molecules in the interlayer space can be exchanged with other anions exploiting the difference in affinity induced by the host-guest interactions in the interlayer gallery. LDHs consequently are materials easily customizable to fulfil multiple different functions. They have successfully been used as catalysts, solid electrolytes, drug delivery vectors and adsorbents ${ }^{4,6-14}$.

While the properties and applications of the LDHs have been widely investigated on a laboratory scale, their commercial use is severely constrained by their low specific surface area, typical for layered, clay-like materials. A larger surface area, competitive with alternative porous materials could be within reach by creating structures with a hierarchical 3D morphology of interconnected mesopores. Combining micro- and mesoporosity in LDH structures exhibiting hierarchical porosity is a promising route to improve their adsorptive and diffusional properties. The development of LDH-based hierarchical structures, however, remains a challenge ${ }^{15,16}$.

Recent attempts to impose a 3D hierarchy on $\mathrm{LDH}$ s include supported $\mathrm{Fe}_{3} \mathrm{O}_{4} @ \mathrm{CuNiAl}$ - LDH submicrospheres ${ }^{17}, \mathrm{Fe}_{3} \mathrm{O}_{4} / \mathrm{LDH}$ core/shell nanospheres ${ }^{18}$, LDH supported on $\mathrm{NiCO}_{2} \mathrm{O}_{4}$ nanowires ${ }^{19}$ or carbon nanotubes ${ }^{20}$. While such composites exhibit interesting functions, the support can block access to the pore system or interfere with the function of the LDH. Reports on self-supported hierarchical LDH structures have hitherto been limited to nanocones ${ }^{21}$, nanospheres ${ }^{22}$, microspheres ${ }^{23}$ and nanoscrolls ${ }^{24}$. Rodriguez et al..$^{25}$ have recently described a post-synthetic route to pierce holes in LDH sheets by fast decomposition of hydrogen peroxide, intercalated between the hydroxide layers after synthesis. This strategy successfully yielded 20-nanometre-wide mesopores in the originally microporous matrix, leading to a 6-fold increase in the specific surface area of the LDHs. Likewise, the production of single layer LDH nanosheets either during synthesis or by post-synthesis delamination has been achieved, successfully creating high specific surface area materials, but failing in 


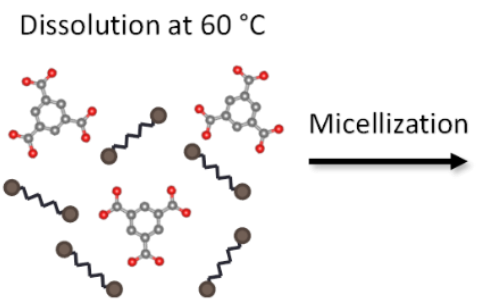

Worm-like micelles
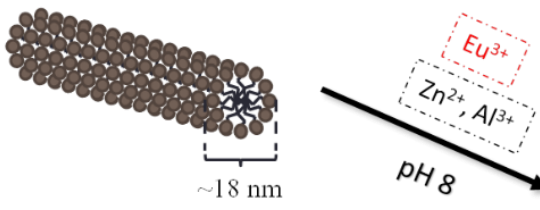

ค.

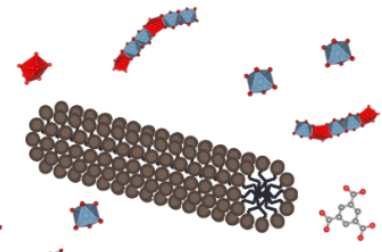

21.

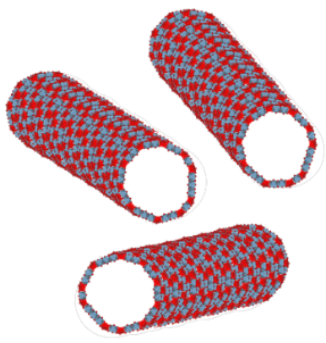

Template
removal
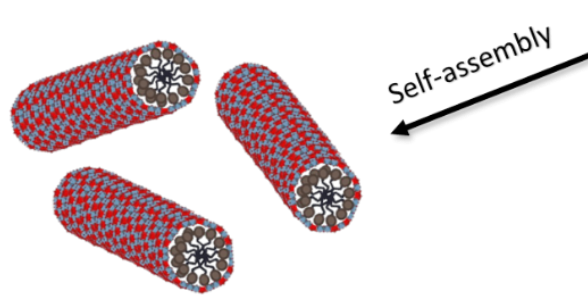

2.

4.

ช

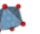
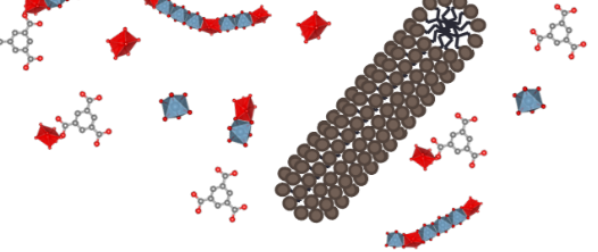

a

ons P-123

\%

$\mathrm{Zn}^{2+} / \mathrm{Al}^{3+}$-centred octahedron

$\mathrm{Eu}^{3+}$-centred non-octahedral polyhedron

Figure 1. Schematic representation of the formation of the LDH nanotubes.

generating a mesoporous 3D hierarchy ${ }^{26-28}$. Pillaring is another strategy that has yielded mesoporous LDHs. In this approach large anionic species are intercalated between the sheets, thereby exposing the interlayer surface. The gallery height is, however, limited to the size of the anionic molecule, typically in the range from 1 to $3 \mathrm{~nm}^{29}$.

Templating approaches aiming at inducing self-assembly of sheet-like minerals onto a convex soft-template surface tend to fail. In the case of LDH for example, the metal cations contained within the hydroxide layers are typically octahedrally coordinated. This yields lamellar solids exhibiting high rigidity with respect to transverse distortions ${ }^{30,31}$. However, in a related class of sheet-like hydroxides, the layered rare earth hydroxides (LREH), the hydroxide sheets exhibit a sinusoidal wave-like topology resulting from the 7-, 8- or 9-fold, non-octahedral coordination of the rare earth cations ${ }^{32}$. Such rare-earth cations, e.g. $\mathrm{Eu}^{3+}$, have also been successfully incorporated in the hydroxide layers of LDHs, retaining an 8-fold coordination ${ }^{33-}$ 35. Doping trivalent rare earth elements $\left(\mathrm{RE}^{3+}\right)$ into $\mathrm{LDH}$ sheets could provide opportunities to allow the curvature of LDH hydroxide layers and enable a soft templating strategy ${ }^{36}$ involving self-assembly of the hydroxide sheets onto convex soft-template surfaces. This manuscript reports on the selfassembly of self-supported ZnAIEu LDH nanotubes using a Pluronic $^{\circledR}$ P-123 worm-like ${ }^{37-40}$ micelle-based soft-templating strategy in combination with the incorporation of $\mathrm{Eu}^{3+}$ cations in the LDH sheets to enable transverse curvature of the hydroxide layers. This strategy leads to the formation of welldefined, multi-walled, hollow, cylindrical LDH nanotubes with typical central gallery of $20 \mathrm{~nm}$. Heteromorphic equimolar substitution of $\mathrm{Al}^{3+}$ by 8 -fold coordinated $\mathrm{Eu}^{3+}$ in $\mathrm{Zn}^{2+} / \mathrm{Al}^{3+} \mathrm{LDHs}$ intercalated with 1,3,5-benzenetricarboxylate anions (BTC) introduces highly coordinated sites into the hydroxide layers, allowing them to selectively align towards the convex surface of the micelles. Exclusion of $\mathrm{Eu}^{3+}$ from the synthesis, prevents formation of the nanotubular morphology, but still produces a net of interconnected cylindrical mesopores embedded in a micrometric LDH phase. The surface area of the latter materials remains 5-fold higher than that of standard flake-like LDHs.

\section{Synthesis}

Mesoporous $\mathrm{LDH}$ with nominal composition $\left[\mathrm{Zn}_{2} \mathrm{Al}_{1}\right.$ $\left.{ }_{x} \mathrm{Eu}_{x}(\mathrm{OH})_{6}\right] \cdot\left(\mathrm{BTC}^{3-}\right)_{0.33} \cdot \mathrm{pH}_{2} \mathrm{O}$, dubbed ZnAl-BTC-P123 for $\mathrm{X}=0$ and ZnAlEuX-BTC-P123 for $X=0.5,1,3,5,10$ and 15\%, were synthesized by coprecipitation of $\mathrm{Zn}^{2+}, \mathrm{Al}^{3+}$ and $\mathrm{Eu}^{3+}$ in alkaline solution containing BTC and Pluronic ${ }^{\circledR} \mathrm{P}-123$ worm-like micelles (see Figure 1). To prepare the micelles, $200 \mathrm{~mL}$ of a solution containing 0.15 wt\% P-123 and $11.5 \times 10^{-3} \mathrm{~mol}^{-L^{-1}}$ BTC and whose $\mathrm{pH}$ was adjusted to $\mathrm{pH} 8$ with addition of sodium hydroxide were heated to $60^{\circ} \mathrm{C}$ to complete dissolution of the components and subsequently cooled to room temperature. Another heat cycle to $60{ }^{\circ} \mathrm{C}$ was done to optimize the micellization. To prepare the $\mathrm{LDHs}, 10 \mathrm{~mL}$ of a solution containing the metal precursors $\mathrm{Zn}\left(\mathrm{NO}_{3}\right)_{2} \cdot 6 \mathrm{H}_{2} \mathrm{O}, \mathrm{Al}\left(\mathrm{NO}_{3}\right)_{3} \cdot 9 \mathrm{H}_{2} \mathrm{O}$ and $\mathrm{Eu}\left(\mathrm{NO}_{3}\right)_{3} \cdot 6 \mathrm{H}_{2} \mathrm{O}$ in the ratio $2: 1-\mathrm{X}: \mathrm{X}$ and total metal concentration of 1 mol.L $\mathrm{L}^{-1}$ (see Table S1) were dosed at a rate of $10 \mathrm{~mL} . \mathrm{h}^{-1}$ into the solution containing the BTC and the micelles. The $\mathrm{pH}$ of the synthesis solution was stated at $\mathrm{pH} 8$ by a Metrohm 848 Titrino plus automatic titrator. Finished the metal solution, the resulting suspension was aged statically in a closed vessel at $60{ }^{\circ} \mathrm{C}$ for two days, followed by centrifugation and rinsing with distilled water. To remove P-123 from the samples, the resulting slurry was re-suspended twice in 

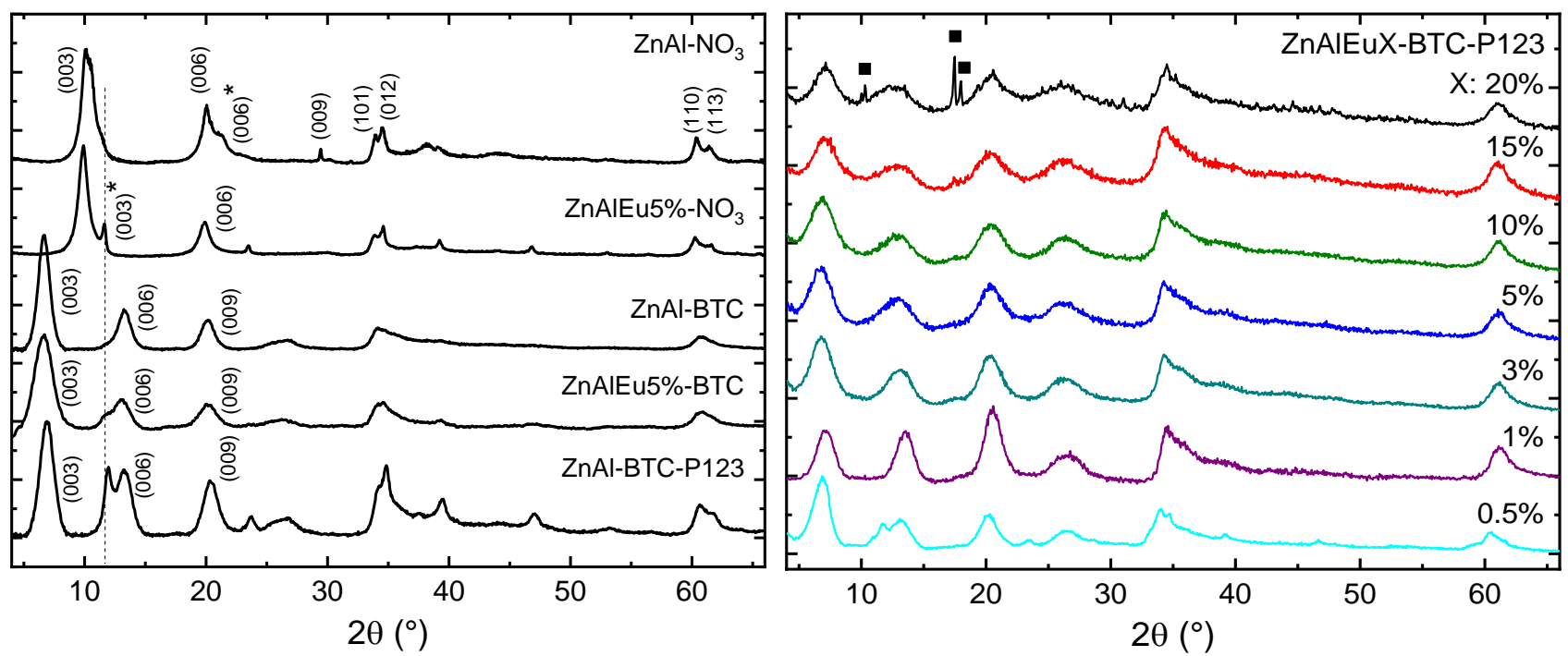

Figure 2. PXRD patterns of flake-like (left) and nanotubular (right) LDH samples. The Miller indexes refer to a 3 -layer hexagonal unit cell. Contamination of the $\mathrm{LDH}^{-}$with $\mathrm{CO}_{3}{ }^{2-}$ was revealed by the PXRD patterns showing additional basal reflections related to the formation of carbonate-intercalated LDHs (starred Miller indexes and vertical dotted line). The squared peaks are attributed to the Eu(BTC) complex, formed in the sample ZnAIEu20\%-BTC-P123.

methanol and sonicated for $15 \mathrm{~min}$. The material was dried in oven at $60^{\circ} \mathrm{C}$ for three days. Flake-like $\mathrm{LDHs}$ with nominal composition

$\left[\mathrm{Zn}_{2} \mathrm{Al}_{0.95} \mathrm{Eu}_{0.05}(\mathrm{OH})_{6}\right] \cdot\left(\mathrm{NO}_{3}{ }^{-}\right) \cdot \mathrm{zH}_{2} \mathrm{O}$,

$\left[\mathrm{Zn}_{2} \mathrm{Al}(\mathrm{OH})_{6}\right] \cdot\left(\mathrm{NO}_{3}{ }^{-}\right) \cdot \mathrm{yH}_{2} \mathrm{O}$, and $\left[\mathrm{Zn}_{2} \mathrm{Al}_{0.95} \mathrm{Eu}_{0.05}(\mathrm{OH})_{6}\right] \cdot\left(\mathrm{BTC}^{3-}\right)_{0.33} \cdot \mathrm{wH}_{2} \mathrm{O}$, dubbed, respectively, $\mathrm{ZnAl}-\mathrm{NO}_{3}, \mathrm{ZnAlEu} 5 \%-\mathrm{NO}_{3}$ and $\mathrm{ZnAlEu} 5 \%-\mathrm{BTC}$, were synthetized with the same synthetic procedure, but without addition of $\mathrm{P}$ 123 and without heating. For $\mathrm{ZnAl}-\mathrm{NO}_{3}$ and $\mathrm{ZnAlEu} 5 \%-\mathrm{NO}_{3}$ no BTC was added (see Table S1). The experimental chemical composition of all investigated samples is shown in Table $\mathbf{S 2}$.

\section{Results and Discussion}

\section{Structural characterization}

Figure 2 depicts the powder X-ray diffraction (PXRD) patterns of all LDH samples investigated. A summary of the main features derived from the analysis of the PXRD data is presented in Table S3. Indexing of the diffraction pattern for the $\mathrm{Zn}^{2+} / \mathrm{Al}^{3+} \mathrm{LDH}$ intercalated with nitrate $\left(\mathrm{ZnAl}-\mathrm{NO}_{3}\right)$ revealed a rhombohedrally-centred hexagonal unit cell with space group $\mathrm{R} \underline{3} \mathrm{~m}$ (see Table S4) and unit cell dimensions $\mathrm{a}=\mathrm{b}=3.064 \AA$ A and $\mathrm{c}=26.856 \AA$, consistent with previous reports on this material ${ }^{41}$. The (003) and (006) basal reflections can be observed at $9.88^{\circ}$ and $19.86^{\circ} 2 \theta$ respectively, revealing a basal spacing $d_{(003)}$ of $8.95 \AA$, characteristic of nitrate-intercalated $\mathrm{LDHs}^{41}$. From the (110) reflection at $60.43^{\circ} 2 \theta$, the metal-to-metal distance between neighbouring, edge-sharing $\mathrm{Zn}(\mathrm{OH})_{2}$ and $\left[\mathrm{Al}(\mathrm{OH})_{2}\right]^{+}$ octahedra forming the rigid hexagonal $2 \mathrm{D}$ arrangement in the hydroxide layer ( $a b$ plane) can be calculated: ' $a=2 d_{(110)}=3.06$ $\AA^{\prime 42}$. The position and relative intensities of the (10/) and $(01 /)$ Bragg reflections reveal $\mathrm{ZnAl}-\mathrm{NO}_{3}$ to predominantly present the $3 \mathrm{R}_{1}$ polymorphism ${ }^{43}$, characterized by an ordered stacking sequence given by the vector $2 / 3 \vec{a}+1 / 3 \vec{b}+1 / 3 \vec{c}$ (Figure S1).

Upon inclusion of $\mathrm{Eu}^{3+}$, the $\mathrm{LDH}$ retains the ordered stacking of the hydroxide layers as revealed by the PXRD pattern of
ZnAlEu5\%-NO $\mathrm{NO}_{3}$, presenting the same features as observed for $\mathrm{ZnAl}-\mathrm{NO}_{3}$. Compared to pure $\mathrm{ZnAl}-\mathrm{NO}_{3} \mathrm{LDH}$, the $(00 /)$ basal reflections for $\mathrm{ZnAlEu} 5 \%-\mathrm{NO}_{3}$ are broadened, a feature related to the smaller crystallite size induced by the introduction of $\mathrm{RE}^{3+}$ ions in the hydroxide layers. Similar observations have been reported previously ${ }^{44}$. In addition to the smaller crystallite size, also the higher coordination number ${ }^{45,46}$ and higher ionic radius of $\mathrm{Eu}^{3+}$ (1.206 $\AA$, typical 8-fold coordination) as compared to $\mathrm{Al}^{3+}$ and $\mathrm{Zn}^{2+}(0.880$ and $0.675 \AA$, respectively, in octahedral coordination) contribute to the broadening of the diffraction features by inducing distortions in the hydroxide layers. As long as $\mathrm{Eu}^{3+} /\left(\mathrm{Al}^{3+}+\mathrm{Eu}^{3+}\right)$ ratios do not exceed $15 \%$, no segregation of the rare earth ion was observed. Only for ZnAIEu20\%-BTC-P123, PXRD reflections related to the formation of the Eu(BTC) complex were observed (squared peaks in Figure 2) ${ }^{47}$

Intercalation of BTC increases the interlayer distance, shifting the (003) basal reflection of BTC-intercalated LDHs to lower $2 \theta$ as compared to $\mathrm{ZnAl}-\mathrm{NO}_{3}$. For $\mathrm{ZnAl-BTC,} \mathrm{ZnAlEu5 \% -}$ BTC, ZnAl-BTC-P123 and ZnAlEuX-BTC-P123 (X = 0.5, 1, 3, 5, 10 and $15 \%)$ the (003) basal reflection appears at, respectively, $6.71,6.69,6.91,6.85,6.66,6.75,6.80,6.95,7.00$ and $7.15^{\circ} 2 \theta$, indicating a basal spacing ranging from 12.4 to $13.4 \AA$. Accounting for the expected thickness of the hydroxide layer $\left(\sim 4.8 \AA^{42}\right)$, the interlayer distance matches the longitudinal size of BTC, suggesting a transverse orientation of this interlayer anion with respect to the hydroxide layers ${ }^{48}$. In addition to the symmetric broadening of the (00/) Bragg reflections, the (101) and (012) peaks are asymmetrically broadened by the intercalation of BTC. This "shark fin" profile has been described in the literature to be associated with periodicity disorder in the [10/] and [01/] directions caused by geometric incompatibilities between the position of the cations in the hydroxide layers and the position of the negative charges of the intercalated anions ${ }^{49}$. 

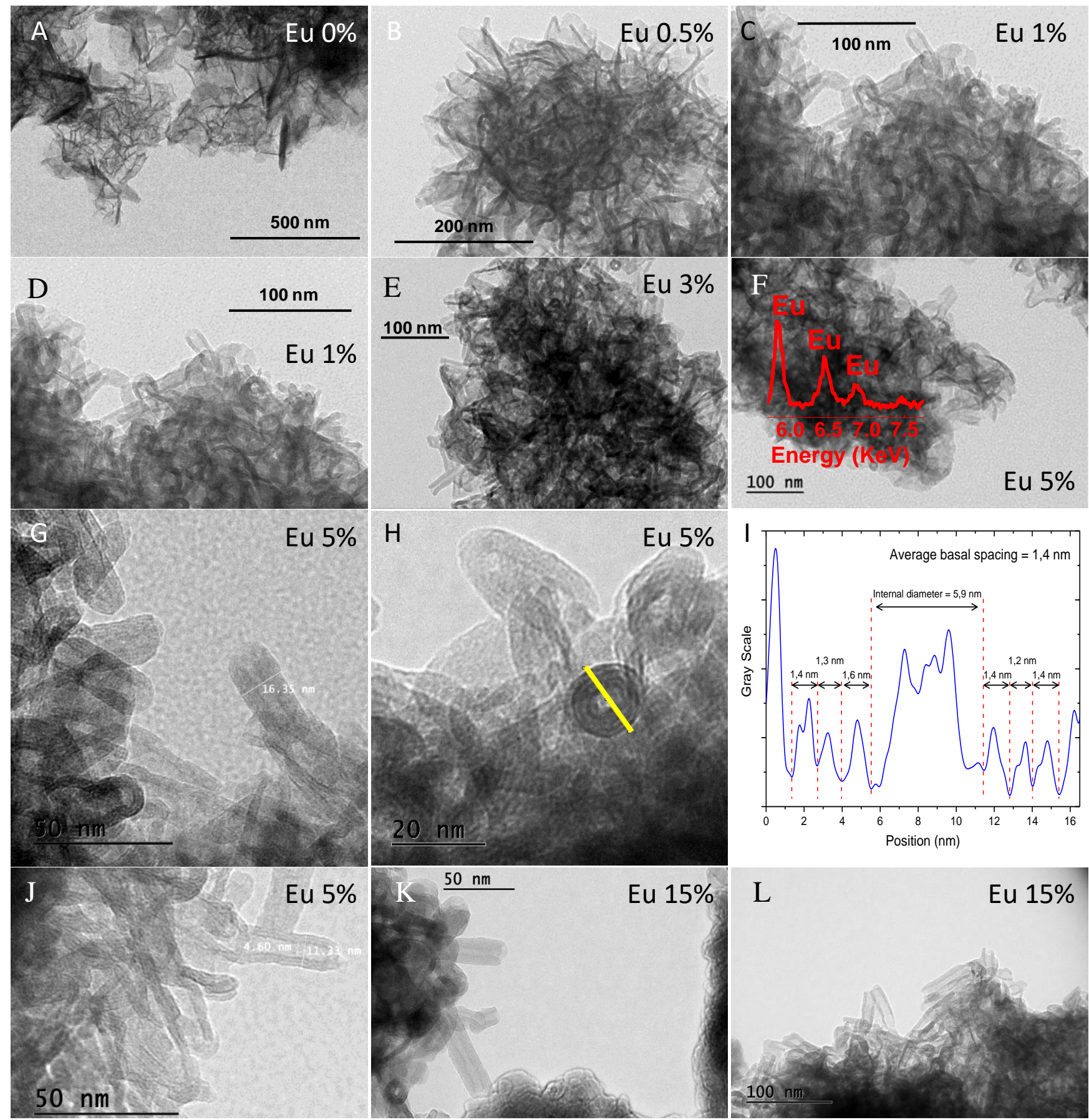

Figure 3. TEM micrographs of the samples (A) ZnAl-BTC-P123 and (B-H, J-L) ZnAlEuX-BTC-P123 (X=0, $0.5,1,3,5$ and $15 \%)$, and (I) pixel profile along the yellow line shown in (H). The inset in $(F)$ depicts the EDX spectrum of the area shown in the picture and confirms the incorporation of Europium in the nanotubular structure.

\section{Morphological characterization}

Scanning and transmission electron microscopy (SEM and TEM, respectively) are ideal tools to gain access to the $\mathrm{LDH}$ morphology and reveal morphological changes induced by the incorporation of $\mathrm{Eu}^{3+}, \mathrm{BTC}$ and/or P-123 in the synthesis. As shown in Figure S2, introduction of BTC and P-123 into the synthesis (ZnAl-BTC-P123, Figure S2 B) does not affect the flakelike morphology of the $L D H$, but does cause a decrease in particle size as compared to the nitrate-intercalated $\mathrm{ZnAl}-\mathrm{NO}_{3}$ $\mathrm{LDH}$ (Figure S2 A). Similarly, also the introduction of $\mathrm{Eu}^{3+}$ and/or the micellar template P-123 leads to the formation of nitrateintercalated, flake-like LDH crystals only (see Figure S3). The combined addition of BTC, $\mathrm{P}-123$, and $\mathrm{Eu}^{3+}$ at concentrations between 5 (Figure S2 C) and 15\% (Figure S2 D), however, leads to the formation of sponge-like aggregates of filiform particles.

This morphological evolution, induced by the combined influence of heteromorphic substitution of $\mathrm{Al}^{3+}$ with $\mathrm{Eu}^{3+}$, intercalation of BTC and synthesis in presence of P-123 (samples ZnAlEuX-BTC-P123) has been evaluated using TEM as a function of the $\mathrm{Eu}^{3+}$ concentration in the synthesis $(X=0.5,1,3,5$ and 

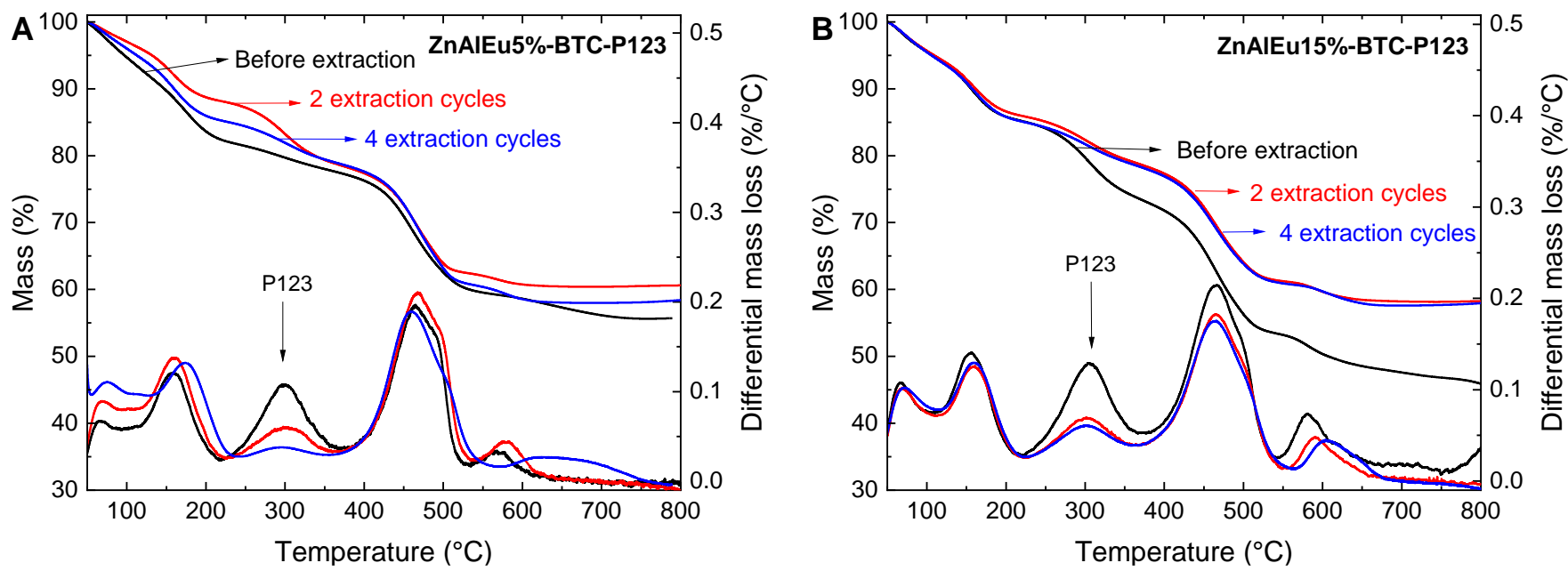

Figure 4. Thermogravimetric analyses (TG and DTG) of ZnAIEu5\%-BTC-P123 (A) and ZnAIEu15\%-BTC-P123 (B) before and after successive extraction cycles comprising washing with methanol, sonication and centrifugation.

15\%; Figure 3). Only in absence of $\mathrm{Eu}^{3+}$, LDHs with rigid, flat layer morphologies are observed. Already at the lowest $\mathrm{Eu}^{3+}$ concentration evaluated (i.e., $\mathrm{X}=0.5 \%$ ) some curvature appears. At concentrations exceeding 1\%, nanotubular structures are observed, and for $\mathrm{Eu}^{3+}$ fractions of $5 \%$ (Figure 3 F-J) and $15 \%$ (Figure 3 K-L), a network of interconnected nanotubes with a large variability in external diameters is formed ( $\varnothing 12-36 \mathrm{~nm}$, see histograms in Figure S4).

Figure $3 \mathbf{H}$ highlights a nanotube of about $16 \mathrm{~nm}$ external diameter. The darker pixels correspond to denser regions, whereas the lighter areas correspond to regions with lower electron density. A set of four concentric rings are visible at frontal view, evidencing the concentric layer-like structure of the LDH nanotubes. By observing the pixel profile along the yellow line, as shown in Figure $\mathbf{3} \mathbf{~}$, information on the basal spacing $(1.4 \mathrm{~nm})$, internal $(5.9 \mathrm{~nm})$ and external $(16 \mathrm{~nm})$ diameters of this particle is obtained. The basal spacing is in agreement with that derived from PXRD. Using EDX (inset in Figure $3 \mathbf{F}$ and Figure S5), the incorporation of Europium in the nanotubular structure was confirmed.

\section{Extraction of the polymeric template}

The synthesis of the LDH nanotubes uses P-123 as a structure directing agent. After synthesis, it is necessary to remove the polymeric template from the mesopores. In general, removal of P-123 from porous matrices can be achieved by post-synthetic solvent extraction or by decomposition of the polymeric molecules (e.g. by calcination, oxidative ozone treatment or microwave digestion $)^{50-52}$. In the present case, the template was successfully extracted using methanol in combination with sonication and centrifugation. This mild procedure not only prevents damage to the nanotubes, it also demonstrates how easily large molecules can enter and exit the central gallery of the mesostructure. Successful removal of P-123 was monitored by differential thermogravimetry (DTG) and $\mathrm{N}_{2}$ physisorption (infra). DTG curves of as-synthesized ZnAIEu5\%-BTC-P123 and ZnAlEu15\%-BTC-P123 show four important mass loss events (Figure 4). Following the elimination of interlayer and adsorbed water at temperatures lower than $100^{\circ} \mathrm{C}$, the events observed at 150,300 and $470{ }^{\circ} \mathrm{C}$, correspond to dehydroxylation of the hydroxide layers ${ }^{53}$, the decomposition of $\mathrm{P}_{123^{54}}$ and the decomposition of BTC, respectively ${ }^{55}$. A significant decrease in the mass loss event around $300{ }^{\circ} \mathrm{C}$ is observed after postsynthetic methanol extraction (4 cycles), demonstrating effective removal of $\mathrm{P}-123$ from the sample.

\section{$\mathrm{N}_{2}$ physisorption}

Nitrogen physisorption and porosimetry provide access to the characteristics of the pore structure and specific surface area of micro- and mesoporous materials. Figure $\mathbf{5}$ and Table $\mathbf{2}$ provide the nitrogen adsorption isotherms and the derived BET specific surface area and $\mathrm{BJH}$ pore volume for flake-like and nanotubular LDH samples. Flake-like LDHs (ZnAlEu5\%-BTC and ZnAl- $\mathrm{NO}_{3}$ ) feature a low BET specific surface area (24 and $1.5 \mathrm{~m}^{2} . \mathrm{g}^{-1}$, respectively) and a small BJH pore volume (0.22 and 0.008 $\mathrm{cm}^{3} . \mathrm{g}^{-1}$, respectively). Their pore size distribution curves (see inset in Figure 5) do not reveal an appreciable amount of mesopores in these samples (region $>2 \mathrm{~nm}$ ), demonstrating that the porosity in these materials originates mainly from the interlayer galleries. The absence of mesoporosity and occupation of the inter-layer galleries by anions and water molecules explain the low BET surface area of these flake-like LDHs.

Figure $\mathbf{5}$ B compares the Nitrogen adsorption-desorption isotherms and pore size distribution curves for ZnAlEu15\%-BTCP123 before and after methanol extraction of the soft template $\mathrm{P}-123$. Before methanol extraction, the nanotubes feature a pore volume comparable to that of flake-like LDHs (Table 2). Following extraction of the soft-template, a network of interconnected mesopores becomes accessible in the nanotubes. Extraction of P-123 leads to a 2 -fold increase in the specific surface area, from 68 to $122 \mathrm{~m}^{2} \cdot \mathrm{g}^{-1}$, a change which is also accompanied by an increase in both the specific pore volume (Table 2 ) and in the number of accessible mesopores in the region from 3 to $30 \mathrm{~nm}$ (see inset in Figure 5 B). Comparing the isotherms for ZnAlEu5\%-BTC-P123 (nanotubes, after 


\begin{tabular}{ccc}
\hline Table 2. Nitrogen adsorption data & & \\
\hline Sample & BET surface area $\left(\mathrm{m}^{2} \cdot \mathrm{g}^{-1}\right)$ & BJH pore volume $\left(\mathrm{cm}^{3} \cdot \mathrm{g}^{-1}\right)$ \\
\hline ZnAl-NO & 1.5 & 0.0080 \\
ZnAlEu5\%-BTC & 24 & 0.22 \\
ZnAIEu0\%-BTC-P123 & 130 & 0.82 \\
ZnAIEu0.5\%-BTC-P123 & 118 & 0.84 \\
ZnAIEu1\%-BTC-P123 & 138 & 0.84 \\
ZnAIEu3\%-BTC-P123 & 122 & 0.73 \\
ZnAlEu5\%-BTC-P123 & 127 & 0.77 \\
ZnAIEu10\%-BTC-P123 & 120 & 0.70 \\
ZnAlEu15\%-BTC-P123 & 122 & 0.55 \\
ZnAIEu15\%-BTC-P123-before extraction & 68 & 0.25 \\
\hline
\end{tabular}

methanol extraction) and ZnAIEu5\%-BTC (flake-like LDHs), two samples exhibiting an identical chemical composition, but different morphology - flake-like vs. nanotubes -, it is evident that the nanotubular morphology provides a 5-fold higher specific surface area. In comparison with the flake-like samples, the nanotubular samples exhibit a hysteresis in the adsorptiondesorption isotherms starting at a lower $P / P_{0}(\approx 0.45)$. The shape of the hysteresis is consistent with the presence of cylindrical mesopores in the central gallery of the nanotubes ${ }^{56,57}$. The pore size distribution curves for the LDH nanotubes reveal a broad distribution of mesopores with apparent diameter in the range from 12 to $25 \mathrm{~nm}$, in addition to the micropores present in all samples. Taking the wall thickness of the nanotubes into account $(8-11 \mathrm{~nm})$, these mesopore diameters are consistent with the diameter of the tubular central gallery, previously derived from electron microscopy. Peculiarly, also the ZnAl-BTC-P123 sample, for which the formation of nanotubes was not observed, exhibits a specific surface area comparable to that of the samples containing nanotubes. Carefully inspecting the scanning electron micrographs of this sample (Figure S2 B), a series of slits can be observed. These slits have dimensions compatible with the diameter of the P-123 micelles, suggesting that the soft template acted as an aggregation centre for the platelets. The use of P-123 would therefore serve as a way to produce porous LDH foams with high specific surface area even without the modification of the particle morphology.

\subsection{Europium coordination and local environment}

The occurrence of local distortions and stacking disorders as result of the inclusion of $\mathrm{Eu}^{3+}, \mathrm{BTC}$ and $\mathrm{P} 123$ renders a full structural determination by diffraction methods very challenging. Photoluminescence spectroscopy and X-ray Absorption Spectroscopy (XAS), however, also reveal the local chemical environment of Europium and its coordination, enabling to assess its impact and implications for the 3D morphology of the LDHs. XAS data (XANES and EXAFS) for the Eu L'II-edge, as well as PL data were collected and analysed for the $\mathrm{Eu}^{3+}$-substituted LDHs. The Eu L"I-edge XANES data is shown in Figure $\mathbf{S 6}$ and reveals an intense whiteline centred at $6983.1 \mathrm{eV}$, consistent with a +III oxidation state of Europium. No indication for the presence of $\mathrm{Eu}(\mathrm{II})$, expected at $6975 \mathrm{eV}$, was observed $^{58}$.

Examining the EXAFS data, the first coordination shell of Eu can be described with an 8-fold coordination with Oxygen at a distance of $2.4 \AA$ (see Figure 6 A and Table 3). Such coordination environment is very similar to what has been reported for the coordination of $\mathrm{Eu}^{3+}$ in $\mathrm{LREH}^{32}$. The Oxygen atoms coordinating
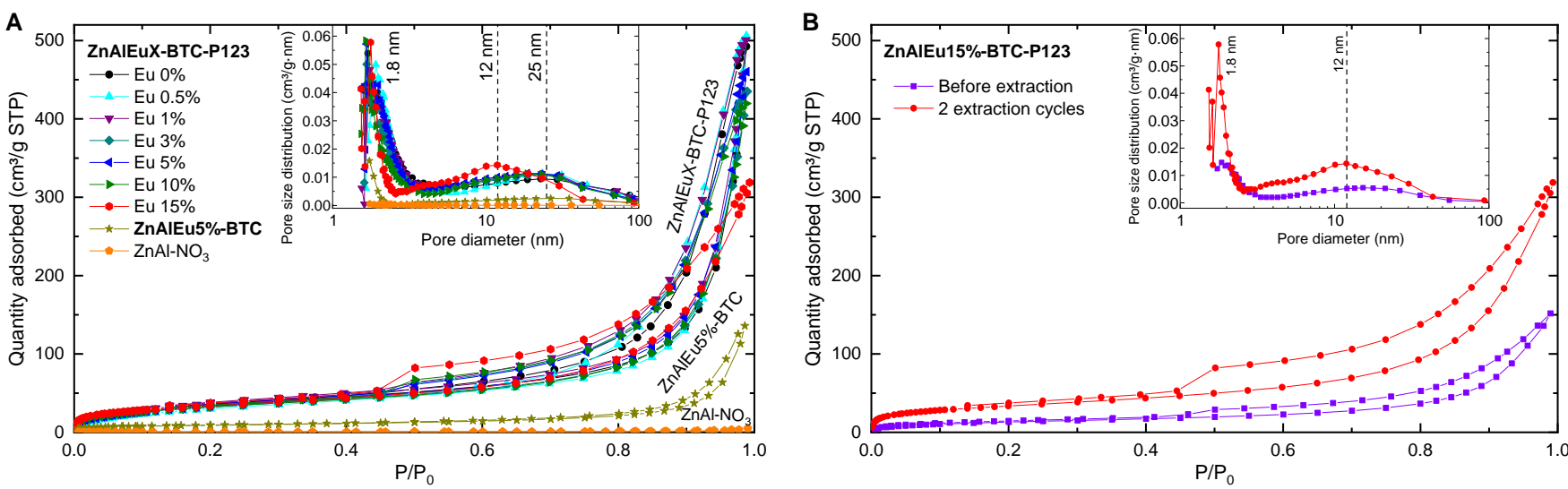

Figure 5. (A) Nitrogen adsorption-desorption isotherms and (inset) pore distribution curves for ZnAl-BTC-P123 and ZnAlEuX-BTC-P123 (X = 0.5, 1, 3, 5, 10 and 15\%, mesoporous $\mathrm{LDHs}$ ) after extraction of P-123, and for $\mathrm{ZnAl}-\mathrm{NO}_{3}, \mathrm{ZnAlEu} \%$-BTC (flake-like LDHs). (B) Effect of the template removal by methanol extraction on the adsorption-desorption isotherms. The vertical dashed lines in the inset indicate the peaks in the mesopore region. 


\begin{tabular}{l}
\multicolumn{4}{l}{ Table 3. First shell fit for the Eu L'I--edge EXAFS data for the samples } \\
ZnAlEuX-BTC-P123*. \\
\begin{tabular}{cccc}
\hline Sample $(\mathrm{X})$ & $\mathrm{N}^{\mathrm{A}}$ & $\mathrm{R}(\AA)^{\mathrm{B}}$ & $\sigma^{2}\left(\AA^{2}\right)^{\mathrm{C}}$ \\
\hline $15 \%$ & $7.96(14)$ & $2.4173(18)$ & $0.0120(4)$ \\
$10 \%$ & $8.33(14)$ & $2.4196(18)$ & $0.0114(4)$ \\
$5 \%$ & $8.0(3)$ & $2.419(3)$ & $0.0104(10)$ \\
$3 \%$ & $7.9(7)$ & $2.420(6)$ & $0.0098(21)$ \\
$1 \%$ & $8.0(10)$ & $2.423(10)$ & $0.010(3)$ \\
$0.5 \%$ & $7.9(11)$ & $2.420(10)$ & $0.010(3)$ \\
\hline
\end{tabular}
\end{tabular}

* An amplitude reduction factor $\mathrm{S}_{0}^{2}=0.95$ has been determined from a $\mathrm{Eu}_{2} \mathrm{O}_{3}$ reference. A single energy shift parameter was co-refined using all data sets: $\Delta E=(3.23 \pm 0.09) \mathrm{eV}$. Global $\mathrm{R}$-factor $=0.28 \%$. The $\mathrm{k}$ fitting range is $2.0-10.5 \AA^{-1}$. The $R$ fitting range is $1.2-2.5 \AA$. A Coordination number. ${ }^{\mathrm{B}}$ Bond distance. ${ }^{\mathrm{C}}$ Debye-Waller factor.

\begin{tabular}{|c|c|c|c|}
\hline Path & $\mathrm{N}^{\mathrm{A}}$ & $\mathrm{R}(\AA)^{\mathrm{B}}$ & $\sigma^{2}\left(\AA^{2}\right)^{C}$ \\
\hline \multicolumn{4}{|c|}{ ZnAlEu15\%-BTC-P123 ${ }^{\mathrm{D}}$} \\
\hline Eu-O & $7.7(3)$ & $2.418(4)$ & $0.0117(9)$ \\
\hline Eu-O & $3.4(9)$ & $3.58(2)$ & $0.0127(6)$ \\
\hline Eu-Zn & 6 (fixed) & $4.01(3)$ & $0.027(5)$ \\
\hline \multicolumn{4}{|c|}{ ZnAlEu10\%-BTC-P123E } \\
\hline Eu-O & $8.0(3)$ & $2.421(4)$ & $0.0108(9)$ \\
\hline Eu-O & $3.3(9)$ & $3.58(2)$ & $0.0107(6)$ \\
\hline Eu-Zn & 6 (fixed) & $4.02(3)$ & $0.0266(5)$ \\
\hline \multicolumn{4}{|c|}{ ZnAIEu5\%-BTC-P123F } \\
\hline Eu-O & $7.8(8)$ & $2.421(8)$ & $0.0098(24)$ \\
\hline Eu-O & $3(2)$ & $3.58(5)$ & $0.0074(13)$ \\
\hline Eu-Zn & 6 (fixed) & $4.03(7)$ & $0.0226(10)$ \\
\hline
\end{tabular}

*An amplitude reduction factor $\mathrm{S}_{0}^{2}=0.95$ was determined from a $\mathrm{Eu}_{2} \mathrm{O}_{3}$ reference. A single energy shift parameter was co-refined using all data sets: $\Delta \mathrm{E}=(3.5 \pm 0.2) \mathrm{eV}$. The $\mathrm{k}$ fitting range is $2.0-10.5 \AA^{-1}$. The $\mathrm{R}$ fitting range is 0.9-4.1 $\AA$. A Coordination number. ${ }^{B}$ Bond distance. C DebyeWaller factor. ${ }^{\mathrm{D}} \mathrm{R}$-factor $=0.45 \%$. ${ }^{\mathrm{E}} \mathrm{R}$-factor $=0.40 \%$. ${ }^{\mathrm{F}} \mathrm{R}$-factor $=0.96 \%$. to Eu most likely belong to hydroxyl groups in the LDH layers, to coordination water and/or to Oxygen atoms of the interlayer anions. More details on the data analysis have been provided in the ESI $\uparrow$. The high coordination number of Europium, as indicated by the EXAFS analysis, contrasts the octahedral coordination commonly observed for the metal cations in LDH materials ${ }^{42}$, implying the hydroxide layers to exhibit local distortions to accommodate these highly coordinated $\mathrm{Eu}^{3+}$ sites.

The Eu L'II EXAFS data for the series of ZnAlEuX-BTC-P123 samples with $X=0.5,1,3,5,10$ and $15 \%$ are all very similar, but exhibit highly different signal-to-noise ratios (see Figure S7 A) which is related to the different $\mathrm{Eu}$ concentration in the samples. Consequently, only the samples with the highest $\mathrm{S} / \mathrm{N}$ ratio and thus the highest Eu concentrations (ZnAlEu5\%-BTCP123, ZnAlEu10\%-BTC-P123 and ZnAlEu15\%-BTC-P123) were selected for a more in-depth analysis of the EXAFS data comprising the first, second and third shells around Eu (Figure 6 B-C and Figure S7 B-D). Detailed inspection of the $\mathrm{k}^{3}$-weighted Fourier transforms, together with the Fourier filtered (inverse Fourier transform) EXAFS spectra (q-spectra) for each coordination shell revealed no sign of high-Z backscatterers, demonstrating a high dispersion of Eu in the samples. This is in line with the PXRD patterns, which also did not reveal any segregation of Eu-rich phases such as $\mathrm{Eu}(\mathrm{OH})_{3}(\mathrm{CN}=9)$ or $\mathrm{EuO}(\mathrm{OH})(\mathrm{CN}=7)^{59,60}$. To fully describe the EXAFS spectra, Eu-O and Eu-Zn single scattering paths were added to the fit, in addition to the 1st oxygen shell, to account for the second and third coordination shells observed in the Fourier transformed data (Figure $6 \mathrm{C}$ ). Attempts to describe the second and third shells by Zinc and Oxygen scatterers, respectively, produced physically impossible values for the fit parameters, as illustrated in Table S5. Overall, the spectra are adequately described (Figure 6 B-C) by 3 Oxygen and 6 (not floated) Zinc atoms at 3.6
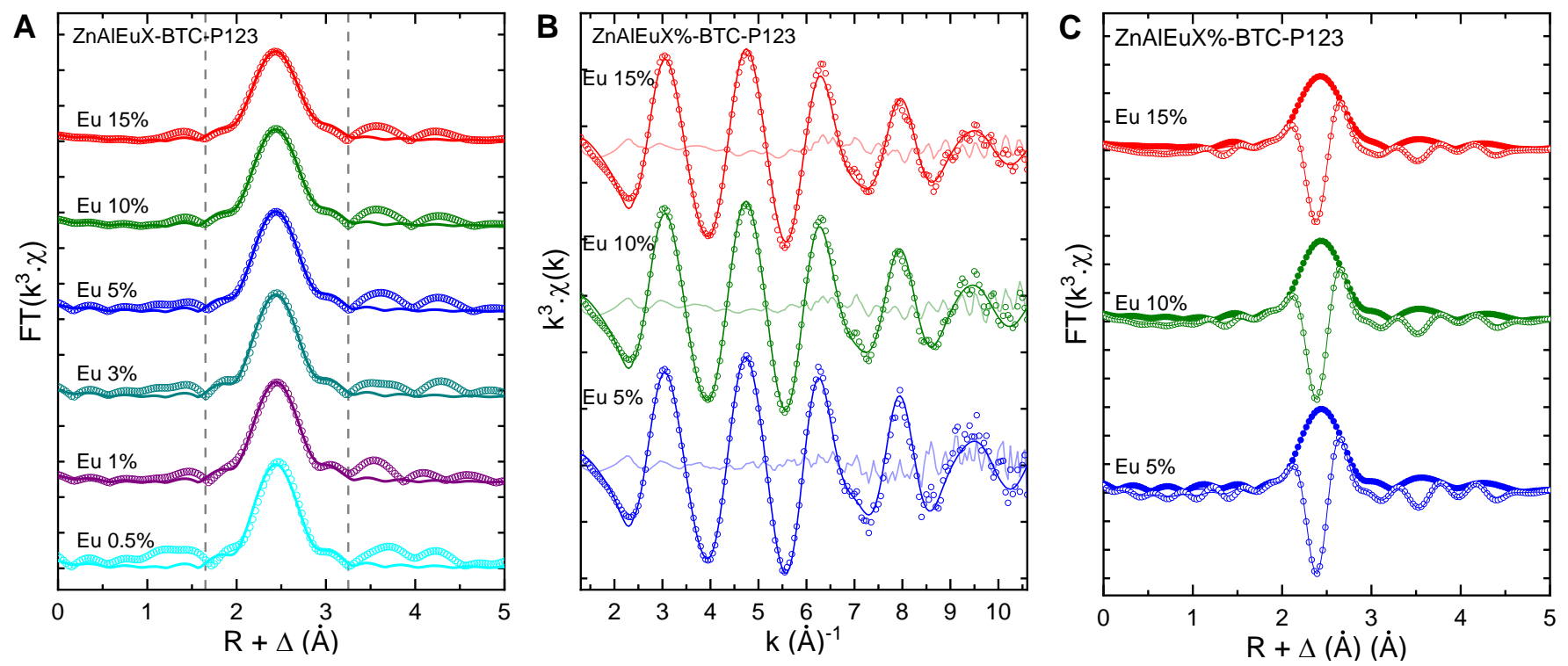

Figure 6. (A) Phase-corrected, Fourier transformed Eu L"'-edge EXAFS data (open circles) and first shell fit (lines) for the samples ZnAlEuX-BTC-P123 (X= $0.5,1,3,5,10$ and $15 \%)$. The fitted region is shown between the vertical dashed lines. For $X=5,10$ and $15 \%$, a fit describing the first, second and third coordination shells is shown in the $k$-space (B) and in the Fourier space (C, magnitude and imaginary part). In B and C, data (open circles), fits (solid lines) and residuals (faint lines) are shown with matching colors for each sample. 

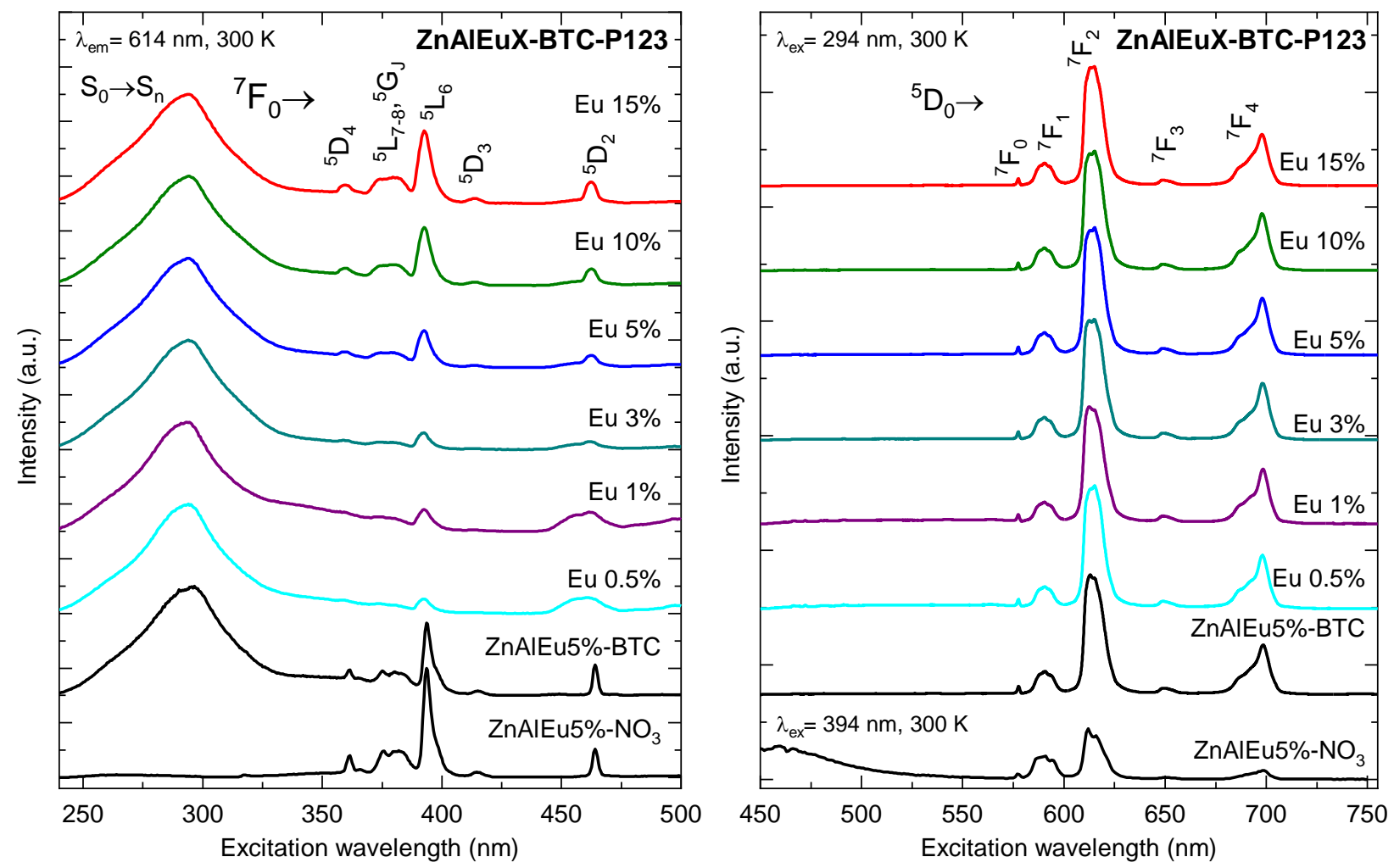

Figure 7. (A) Excitation spectra of the Eu ${ }^{3+}$-substituted LDH samples. The emitted intensity was monitored at $\lambda_{\text {em }}=614 \mathrm{~nm}$, corresponding to the $\left(\text { Eu }{ }^{3+}\right)^{5} D_{0} \rightarrow{ }^{7} F_{2}$ transition The spectra are normalized by the peak intensity of the $S_{0}(\pi) \rightarrow S_{1}\left({ }^{1} \pi^{*}\right)$ excitation band. (B) Emission spectra under excitation at the BTC excitation band (294 nm) or direct excitation of the $\mathrm{Eu}^{3+}$ ion at $394 \mathrm{~nm}$. The emission spectra are normalized by the peak intensity of the host-independent magnetic dipole transition $\left(\mathrm{Eu}^{3+}\right)^{5} D_{0} \rightarrow{ }^{7} F_{1}$.

and 4.0 Å, respectively (Table 4). This Eu-Zn distance, in combination with the thickness of a hydroxide layer $(\sim 4.8 \AA)^{42}$ and the Eu-O distance of around $2.4 \AA$, readily reveals that the Europium ions are hosted in the brucite-like layers. The Eu-Zn distance in this model is considerably longer than that of $\mathrm{Zn}-\mathrm{Al}$ ( 3.06 A) in ZnAl LDHs. This is consistent with the higher ionic radius and the higher metal-O distance in the first shell for $\mathrm{Eu}$ as compared to $\mathrm{Zn}$ and $\mathrm{Al}$.

Further insight into the Eu local environment can be obtained from the analysis of the photoluminescent properties of the LDHs. The excitation spectra of these materials (Figure 7 A, detected at $614 \mathrm{~nm}$ ) are characterized by narrow bands in the spectral region from 350 to $550 \mathrm{~nm}$, assigned to direct excitation of the $4 \mathrm{f}-4 \mathrm{f}$ intraconfigurational transitions of $\mathrm{Eu}^{3+}$. For samples intercalated with BTC, a broad band from 250 to $325 \mathrm{~nm}$ is observed, corresponding to the excitation of the benzenecarboxylate with the subsequent energy transfer to the $\mathrm{Eu}^{3+}$ activators. Excitation of BTC involves electric dipoleallowed transitions between the ground and excited singlet levels $S_{0}(\pi)$ and $S_{n}\left({ }^{1} \pi^{*}\right)$, respectively. After this first pumping step, non-radioactive relaxation to the triplet state $T_{1}\left({ }^{3} \pi^{*}\right)$ takes place. Since transitions from $\mathrm{T}_{1}\left({ }^{3} \pi^{*}\right)$ to the ground state $\mathrm{S}_{0}(\pi)$ are spin-forbidden, subsequent energy transfer occurs to the quasi-resonant $4 \mathrm{f}$ levels of the $\mathrm{Eu}^{3+}$ ions in the vicinity of BTC, as depicted in Figure S8. Under excitation at the ligand band, the $\mathrm{Eu}^{3+}$-substituted LDHs present strong red emission, characteristic of $\mathrm{Eu}^{3+}$-containing materials (Figure S9). Investigating a set of layered Europium hydroxides (LEuHs) intercalated by aromatic carboxylates with different orientations and -COO: $\mathrm{Eu}^{3+}$ binding modes, Shao et al. ${ }^{48}$ have demonstrated that sensitization of the $\mathrm{Eu}^{3+}$ activators by interlayer BTC only occurs if this anion is transversely positioned in the interlayer galleries with respect to the hydroxide layers and if the -COO- group directly binds to $\mathrm{Eu}^{3+}$. Given the similarity between LDHs and LEUH, the transversal positioning of BTC in the LDHs - as derived from PXRD - and the observation of energy transfer from $\mathrm{BTC}$ to $\mathrm{Eu}^{3+}$ indicate the direct coordination of BTC with $\mathrm{Eu}^{3+}$ also in the LDHs.

The emission spectra (Figure $7 \mathbf{B}$ ) of the $\mathrm{Eu}^{3+}$-containing LDHs present a set of narrow emission bands ascribed to the $\left(\mathrm{Eu}^{3+}\right)^{5} \mathrm{D}_{0} \rightarrow^{7} \mathrm{~F}_{\mathrm{J}}(\mathrm{J}=0-4)$ electronic transitions ${ }^{61}$. The absence of ligand emission in all BTC-intercalated samples reveals the excellent ligand-to-metal energy transfer in these systems, with a reduced probability of energy retro-transfer from $\mathrm{Eu}^{3+}$ to BTC due to the slightly higher energy of the $T_{1}\left({ }^{3} \pi^{*}\right)$ level as compared to the ${ }^{5} \mathrm{D}_{1}$ and ${ }^{5} \mathrm{D}_{0}$ levels of $\mathrm{Eu}^{3+62}$. The relative intensities of the $4 \mathrm{f}-4 \mathrm{f}$ emission bands of the $\mathrm{RE}^{3+}$ ions are sensitive to the chemical environment around the luminescent centre. In a perfectly centrosymmetric environment, very low radiative transition rates are expected for the $\left(\mathrm{Eu}^{3+}\right)^{5} \mathrm{D}_{0} \rightarrow^{7} \mathrm{~F}_{2,4}$ emissions. On the other hand, the intensity of the magnetic dipole transition $\left(\mathrm{Eu}^{3+}\right)^{5} \mathrm{D}_{0} \rightarrow^{7} \mathrm{~F}_{1}$ is largely independent on the host and can be used as an internal standard for the correlation of the luminescent and structural properties of $\mathrm{Eu}^{3+}$-containing materials. In the here investigated LDHs, the $\left(\mathrm{Eu}^{3+}\right)^{5} \mathrm{D}_{0} \rightarrow^{7} \mathrm{~F}_{2}$ emission is the most intense in all spectra, indicating that $\mathrm{Eu}^{3+}$ 


\begin{tabular}{c|cccccccc}
\hline \multicolumn{1}{c}{ Table 5. Optical parameters of the Eu $\mathbf{B}^{3+}$-containing LDHs.* } \\
\hline Sample & $\begin{array}{c}\mathrm{A}_{\text {rad }} \\
\left(\mathrm{ms}^{-1}\right)\end{array}$ & $\begin{array}{c}\mathrm{A}_{\text {nrad }} \\
\left(\mathrm{ms}^{-1}\right)\end{array}$ & $\begin{array}{c}\mathrm{A}_{\text {tot }} \\
\left(\mathrm{ms}^{-1}\right)\end{array}$ & $\mathrm{N}_{\text {oH }}$ & $\begin{array}{c}\tau_{\text {rad }} \\
(\mathrm{ms})\end{array}$ & $\begin{array}{c}\tau_{\text {nrad }} \\
(\mathrm{ms})\end{array}$ & $\begin{array}{c}\tau \\
(\mathrm{ms})\end{array}$ & $\begin{array}{c}\eta \\
(\%)\end{array}$ \\
\hline ZnAlEu5\%-NO & 0.187 & 4.238 & 4.425 & 8.6 & 5.35 & 0.24 & 0.23 & 4.6 \\
ZnAlEu5\%-BTC & 0.582 & 2.865 & 3.448 & 5.6 & 1.72 & 0.35 & 0.29 & 16.9 \\
ZnAlEu0.5\%-BTC-P123 & 0.674 & 2.897 & 3.571 & 5.7 & 1.48 & 0.35 & 0.28 & 18.9 \\
ZnAlEu1\%-BTC-P123 & 0.675 & 2.896 & 3.571 & 5.7 & 1.48 & 0.35 & 0.28 & 18.9 \\
ZnAlEu3\%-BTC-P123 & 0.602 & 2.952 & 3.554 & 5.8 & 1.66 & 0.34 & 0.28 & 16.9 \\
ZnAlEu5\%-BTC-P123 & 0.675 & 2.773 & 3.448 & 5.5 & 1.48 & 0.36 & 0.29 & 19.6 \\
ZnAlEu10\%-BTC-P123 & 0.648 & 2.924 & 3.571 & 5.8 & 1.54 & 0.34 & 0.28 & 18.1 \\
ZnAlEu15\%-BTC-P123 & 0.616 & 2.881 & 3.498 & 5.7 & 1.62 & 0.35 & 0.29 & 17.6 \\
\hline
\end{tabular}

* Uncertainties: $\pm 10 \%$ for Arad, $A_{n r a d}, N_{O H}, \tau_{\text {rad, }} \tau_{\text {nrad }}$ and $\eta ; \pm 5 \%$ for Atot and $\tau$

is in a site with no inversion symmetry. In agreement with the EXAFS results, this clearly rules out the octahedral symmetry commonly observed for the metal sites in LDHs. For noncentrosymmetric crystal fields, the mixing of electronic configurations with opposite parity caused by the odd components of the ligand field partially relaxes the Laporte rule, leading to non-vanishing $4 \mathrm{f}-4 \mathrm{f}$ dipole strengths and increased radiative transition rates ${ }^{63,64}$. Additionally, since the intensity of the $\left(\mathrm{Eu}^{3+}\right)^{5} \mathrm{D}_{0} \rightarrow^{7} \mathrm{~F}_{1}$ transition is host-independent, its tabulated radiative transition rate $\left(A_{M D}=14.73 n^{3} \mathrm{~s}^{-1}\right)$ can used to experimentally determine the total radiative transition probability $\left(\mathrm{A}_{\text {rad }}\right)$ related to the $\left(\mathrm{Eu}^{3+}\right)^{5} \mathrm{D}_{0} \rightarrow^{7} \mathrm{~F}_{1,2,4}$ emissions based on the integral intensities (optical power or spectral irradiance, $\left.\mathrm{S}_{1,2,4}\right)$ and barycentre $\left(\lambda_{1,2,4}\right)$ of the $\left(\mathrm{Eu}^{3+}\right)^{5} \mathrm{D}_{0} \rightarrow^{7} \mathrm{~F}_{1,2,4}$ emission bands as:

$$
\mathrm{A}_{\text {rad }}=\mathrm{A}_{M D} \sum_{J=1,2,4} \frac{\bar{\lambda}_{J}}{\overline{\bar{\lambda}}_{1}} \frac{S_{J}}{S_{1}} .
$$

Here, the refractive index of the LDH matrices $(n)$ has been assumed to be 1.5 in accordance with previously reported investigations ${ }^{65,66}$. Comparison between the radiative decay rates for the nitrate- and BTC-intercalated LDHs shows an enhancement in the photoluminescence intensity of these materials with the intercalation of BTC. This feature clearly points that the coordination environment around $\mathrm{Eu}^{3+}$ is changed with the intercalation of BTC as compared to the nitrate-intercalated LDHs. In order to tentatively characterize these changes, the total decay rate $\left(A_{\text {tot }}=A_{\text {rad }}+A_{\text {nrad }}\right)$ of the $\left(E u^{3+}\right)^{5} D_{0}$ electronic level, comprising both $A_{\text {rad }}$ and nonradiative $\left(A_{\text {nrad }}\right)$ decay rates has been calculated based on the measured lifetime $(\tau)$ of the $\left(E u^{3+}\right)^{5} D_{0}$ level (see Table 5 and Figure S10):

$$
\mathrm{A}_{t o t}=\frac{1}{\tau}
$$

from which the non-radiative transition rate can be experimentally accessed:

$$
\mathrm{A}_{\text {nrad }}=\frac{1}{\tau}-\mathrm{A}_{\text {rad }}
$$

Due to the typically high vibrational energy of the hydroxyl groups, the most important non-radiative decay process in LDHs is mediated by the vibrations on the $\mathrm{O}-\mathrm{H}$ oscillators in the hydroxide layers. The number of $\mathrm{O}-\mathrm{H}$ oscillators $\left(\mathrm{N}_{\mathrm{OH}}\right)$ in the first coordination shell of $\mathrm{Eu}^{3+}$ is directly related to $\mathrm{A}_{\text {nrad }}$ (in $\mathrm{ms}^{-1}$ ) by the Supkowski and Horrocks' empirical formula $65,67,68$ :

$$
\mathrm{N}_{O H}=2.22 \times\left[\mathrm{A}_{\text {nrad }}-0.31\right] .
$$

The results for $\mathrm{N}_{\mathrm{OH}}$ in the LDHs (Table 5) are compatible with a total of 9 and $6 \mathrm{O}-\mathrm{H}$ oscillators in the first coordination shell of the $\mathrm{Eu}^{3+}$ activators in the nitrate- and BTC-intercalate materials, respectively. Combining these numbers with a total coordination number of 8 derived from EXAFS, the Europium first coordination sphere can be deduced to be formed by 6 hydroxyls, one $\mathrm{H}_{2} \mathrm{O}$ (counting two $\mathrm{O}-\mathrm{H}$ oscillators) and one additional Oxygen attributed to an interlayer nitrate in the proximity of the $\mathrm{Eu}^{3+}$ site in $\mathrm{ZnAlEu} 5 \%-\mathrm{NO}_{3}$; and by 6 hydroxyls and 2 Oxygen atoms arising from the direct coordination with BTC in the BTC-intercalated LDHs. Within this interpretation, the enhancement in the PL intensity upon intercalation of the organic moiety can be explained by the replacement of a coordination water and the nitrate anion in the first coordination shell of $\mathrm{Eu}$ by the $-\mathrm{COO}^{-}$group of the benzenecarboxylates. As has already been mentioned above, direct coordination between Eu and BTC in layered hydroxides has also been observed by Shao et al. ${ }^{48}$ in BTC-intercalated $\mathrm{LEuH}$, for which a monodentate coordination mode has been deduced for the Eu-BTC interaction. Layered rare earth hydroxides intercalated with nitrate have also been reported ${ }^{69}$, with the lanthanide ions in the hydroxide layers directly coordinating to one Oxygen from the interlayer anion. Thus, it is reasonable to assume that the coordination environments deduced for $\mathrm{Eu}^{3+}$ in the here reported LDHs are plausible.

From $A_{\text {rad }}$ and $A_{\text {nrad }}$, the radiative $\left(\tau_{\text {rad }}\right)$ and the non-radiative $\left(\tau_{\text {nrad }}\right)$ decay lifetimes can be calculated: $\tau_{\text {rad }}=1 / A_{\text {rad }}$ and $\tau_{\text {nrad }}=$ $1 / A_{\text {nrad. }}$. For all the investigated LDHs, de-excitation of the $\left(E u^{3+}\right)^{5} D_{0}$ level is dominated by non-radioactive decay processes occurring in time scales ( $\tau_{\text {nrad }}=0.26-0.36 \mathrm{~ms}$ ) much shorter than the radioactive decays lifetimes $\left(\tau_{\mathrm{rad}}=1.48-5.35 \mathrm{~ms}\right)$. The high vibrational energy of the $\mathrm{O}-\mathrm{H}$ oscillators, intrinsic of the LDH structure, decreases the number of phonons necessary to promote non-radiative relaxation of the $\left(E u^{3+}\right)^{5} D_{0}$ level. This has the effect to increase the non-radioactive decay probability and decrease the non-radiative decay lifetime and the quantum efficiencies of the emitting level. The quantum efficiencies of 
$\mathrm{Eu}^{3+}$ ions hosted in the hydroxide layers of LDHs (Table 5) are much lower than those observed for the anhydrous Eu-BTC complexes $(\eta \sim 50 \%)^{47}$.

Regardless of the $\mathrm{Eu}^{3+}$ concentration in the LDH nanotubes, all solids exhibit very similar emission profiles, indicating that the $\mathrm{Eu}^{3+}$ ion is found in similar chemical environments in all samples. Furthermore, also very similar emission profiles are observed regardless the excitation is done directly in a $\mathrm{Eu}^{3+}$ energy level or in the ligand excitation band (see Figure S11), showing that the large majority, if not all, of the $\mathrm{Eu}^{3+}$ sites in the LDH solids are in the vicinity of a BTC molecule.

\subsection{Mesostructuring layered materials: mechanistic insights}

Typically, the metal cations hosted within the hydroxide layers of LDHs are octahedrally coordinated to the hydroxyl groups of the LDH sheets. This coordination geometry renders the LDHs to be highly rigid with respect to transverse distortions ${ }^{30,31}$ and then unable to self-assemble onto a convex soft-template surface. On the other hand, as shown by EXAFS, $\mathrm{Eu}^{3+}$ cations are hosted in the hydroxide layers of LDHs with an 8-fold, nonoctahedral coordination, implying that the hydroxide layers exhibit local distortions in order to accommodate these highly coordinated metal sites. Such distortions were also indicated by PXRD and hint on the role of the lanthanide in the self-assembly of the LDH nanotubes. Given the high coordination capacity of $\mathrm{Eu}^{3+}$, one can tentatively explain the formation of this mesostructured phase by the cooperative alignment of the

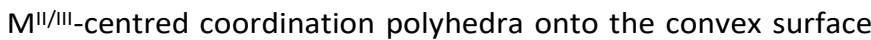
of the P-123 worm-like micelles and the increased stability of a bent $\mathrm{LDH}$ sheet hosting the $\mathrm{Eu}^{3+}$ ions. Within this hypothesis, the local distortions caused by $\mathrm{Eu}^{3+}$ in the hydroxide layers, enable the LDH sheets to accommodate the curvature necessary to stabilize the nanotubes. Interestingly, similarly high coordination numbers for the metal sites in sheet-like hydroxides have been found in LREH, a class of materials closely related to the $\mathrm{LDHs}^{70}$. In those materials, a wave-like sinusoidal topology develops as a result of the 2D packing of nonoctahedral $\left[\mathrm{RE}(\mathrm{OH})_{8}\right],\left[\operatorname{RE}(\mathrm{OH})_{7}\left(\mathrm{H}_{2} \mathrm{O}\right)\right]$ and/or $\left[\mathrm{Eu}(\mathrm{OH})_{8}\left(\mathrm{H}_{2} \mathrm{O}\right)\right]$ polyhedra hosting 8/9-fold coordinated $\mathrm{RE}^{3+}$ sites.

\section{Conclusions}

Self-assembly of self-supported ZnAIEu LDH nanotubes was achieved using a soft-templating strategy combined with the incorporation of $\mathrm{Eu}^{3+}$ cations in the $\mathrm{LDH}$ sheets to enable transverse curvature of the hydroxide layers. After solvent extraction at mild conditions a net of well-defined, multiwalled, hollow, cylindrical LDH nanotubes with accessible mesopores are formed. The nanotubes were characterized by $X$-ray diffraction, scanning and transmission electron microscopy, energy dispersive $\mathrm{X}$-ray spectroscopy, $\mathrm{X}$-ray absorption spectroscopy, $\mathrm{N}_{2}$ physisorption and photoluminescence spectroscopy. Europium is shown to be hosted in the hydroxide layers in an 8-fold Oxygen coordination, implying that the hydroxide layers exhibit local distortions allowing the LDH sheets to selectively align towards the convex surface of the soft template. The specific surface area of the nanotubes is five times higher than that of standard flake-like LDHs. Incorporation of Eu in the ZnAl LDH structure renders these minerals photoluminescent. These features make the LDH nanotubes, high surface area, luminescent hierarchical structures with promising applications in catalysis and nanomedicine.

\section{Author Contributions}

AFM: conceptualization, investigation, data curation, formal analysis, writing - original draft, writing - review \& editing, and funding acquisition. DNFS: investigation, validation, and writing - review \& editing. IGNS: conceptualization, writing - review and editing. $A D$ : investigation. FG: validation and formal analysis. EB: conceptualization, formal analysis, and writing review \& editing. DM: conceptualization, data validation, funding acquisition, project administration and supervision. All authors discussed the results and revised the manuscript.

\section{Conflicts of interest}

There are no conflicts to declare.

\section{Acknowledgments}

The authors acknowledge the Laboratory of Crystallography (IFUSP, São Paulo) for assistance with the PXRD measurements and the National Center for Research in Energy and Materials (CNPEM-LNLS) for concession of beamtime (Proposals No. 20190148 and No. 20180133). The CNPEM-LNLS staff is acknowledged for technical assistance during the experiments. Victoria Valentim Freire is acknowledged for assistance with the data collection at the XAFS2 beamline.

This research was funded by Fundação de Amparo à Pesquisa do Estado de São Paulo (FAPESP, 2015/19210-0 and 2018/13837-0), Coordenação de Aperfeiçoamento de Pessoal de Nível Superior (CAPES, 1723707, Finance Code 001) and Conselho Nacional de Desenvolvimento Científico e Tecnológico (CNPq, 142127/2014-0 and 403055/2016-4).

\section{Notes and references}

X. S. Zhao, J. Mater. Chem., 2006, 16, 623-625.

H. C. Zeng, J. Mater. Chem., 2006, 16, 649-662.

Z. Y. Yuan and B. L. Su, J. Mater. Chem., 2006, 16, 663-677. A. I. Khan and D. O'Hare, J. Mater. Chem., 2002, 12, 31913198.

5 V. Rives, Ed., Layered Double Hydroxides: Present and Future, Nova Science Publishers, New York, 2001. G. Fan, F. Li, D. G. Evans and X. Duan, Chem. Soc. Rev., 2014, 43, 7040-7066.

7 R. M. M. Santos, J. Tronto, V. Briois and C. V. Santilli, J. Mater. Chem. A, 2017, 5, 9998-10009.

8 S. Zhang, F. Yao, L. Yang, F. Zhang and S. Xu, Carbon, 2015, 
93, 143-150. 10744-10766.

A. Khenifi, Z. Derriche, C. Mousty, V. Prévot and C. Forano, Appl. Clay Sci., 2010, 47, 362-371.

L. Feng, A. Li, Y. Li, J. Liu, L. Wang, L. Huang, Y. Wang and X. Ge, ChemPlusChem, 2017, 82, 483-488.

L. Fagiolari, A. Scafuri, F. Costantino, R. Vivani, M.

Nocchetti and A. Macchioni, ChemPlusChem, 2016, 81, 1060-1063.

H. Yuan, Y. Wang, C. Yang, Z. Liang, M. Chen, W. Zhang, H. Zheng and R. Cao, ChemPhysChem, 2019, 20, 2964-2967. D. M. Morales, S. Barwe, E. Vasile, C. Andronescu and W. Schuhmann, ChemPhysChem, 2019, 20, 3030-3036. J. C. Groen, L. A. Peffer and J. Pérez-Ramírez, Microporous Mesoporous Mater., 2003, 60, 1-17. Na and G. A. Somorjai, Catal. Letters, 2015, 145, 193213.

X. Chen, F. Mi, H. Zhang and H. Zhang, Mater. Lett., 2012 69, 48-51.

L. Li, Y. Feng, Y. Li, W. Zhao and J. Shi, Angew. Chemie Int. Ed., 2009, 48, 5888-5892. L. Huang, D. Chen, Y. Ding, S. Feng, Z. L. Wang and M. Liu, Nano Lett., 2013, 13, 3135-3139. J. Zhao, J. Chen, S. Xu, M. Shao, Q. Zhang, F. Wei, J. Ma, M. Wei, D. G. Evans and X. Duan, Adv. Funct. Mater., 2014, 24 2938-2946.

X. Liu, R. Ma, Y. Bando and T. Sasaki, Adv. Mater., 2012, 24 2148-2153.

L. Li, R. Ma, N. Iyi, Y. Ebina, K. Takada and T. Sasaki, Chem. Commun., 2006, 3125-3127. X. Duan, Chem. Mater., 2012, 24, 1192-1197.

M. A. Rocha, P. A. D. Petersen, E. Teixeira-Neto, H. M. Petrilli, F. Leroux, C. Taviot-Gueho and V. R. L. Constantino, RSC Adv., 2016, 6, 16419-16436.

P. Gonzalez Rodriguez, M. De Ruiter, T. Wijnands and J. E. Ten Elshof, Sci. Rep., 2017, 7, 481.

T. Hibino, M. Kobayashi, P. V. Coveney, W. Jones, J. Connolly and P. Jacobs, J. Mater. Chem., 2005, 15, 653.

T. Hibino, Chem. Mater., 2004, 16, 5482-5488.

Q. Wang and D. Ohare, Chem. Rev., 2012, 112, 4124-4155. T. J. Pinnavaia, Encycl. Mater. Sci. Technol., 2001, 70117012.

S. A. Solin and D. R. Hines, Colloids Surfaces A Physicochem Eng. Asp., 2001, 179, 195-199.

\section{F. Thorpe and S. A. Solin, in Access in Nanoporous}

Materials, eds. T. J. Pinnavaia and M. . Thorpe, Springer US, 2002, pp. 59-71.

R. Ma and T. Sasaki, Adv. Mater., 2010, 22, 5082-104. I. G. N. Silva, A. F. Morais, B. C. Lima, F. A. Garcia and D. Mustafa, Appl. Clay Sci., 2020, 199, 105861.

A. F. Morais, I. G. N. Silva, B. C. Lima, F. A. Garcia and D. Mustafa, ACS Omega, , DOI:10.1021/acsomega.0c02848. A. F. Morais, I. G. N. N. Silva, S. P. Sree, F. M. de Melo, G. Brabants, H. F. Brito, J. A. Martens, H. E. Toma, C. E. A. A. Kirschhock, E. Breynaert and D. Mustafa, Chem. Commun.,
2017, 53, 7341-7344.

S. Kerkhofs, T. Willhammar, H. Van Den Noortgate, C. E. A Kirschhock, E. Breynaert, G. Van Tendeloo, S. Bals and J. A Martens, Chem. Mater., 2015, 27, 5161-5169.

R. Ganguly, M. Kumbhakar and V. K. Aswal, J. Phys. Chem. $B, 2009,113,9441-9446$.

R. Ganguly, V. K. Aswal, P. A. Hassan, I. K. Gopalakrishnan and J. V. Yakhmi, J. Phys. Chem. B, 2005, 109, 5653-5658. Y. Kadam, R. Ganguly, M. Kumbhakar, V. K. Aswal, P. A. Hassan and P. Bahadur, J. Phys. Chem. B, 2009, 113, 16296-16302.

A. G. Denkova, E. Mendes and M. O. Coppens, J. Phys. Chem. B, 2009, 113, 989-996.

S. Marappa, S. Radha and P. V. Kamath, Eur. J. Inorg. Chem., 2013, 2122-2128.

X. Duan, D. G. Evans, Y. Kang, A. I. Khan, F. Leroux, B. Li, F. Li, D. O'Hare, R. C. T. Slade, C. Taviot-Gueho, M. Wei and G. R. Williams, Layered Double Hydroxides, Springer Berlin Heidelberg, 1st edn., 2005, vol. 119. A. S. Bookin and V. A. Drits, Clays Clay Miner., 1993, 41, 551-557.

A. W. Musumeci, Z. P. Xu, S. V Smith, R. F. Minchin and D. J. Martin, J. Nanoparticle Res., 2010, 12, 111-120.

T. Posati, F. Costantino, L. Latterini, M. Nocchetti, M. Paolantoni and L. Tarpani, Inorg. Chem., 2012, 51, 1322913236.

Y. Zhao, J.-G. Li, F. Fang, N. Chu, H. Ma and X. Yang, Dalt. Trans., 2012, 41, 12175.

I. G. N. Silva, D. Mustafa, B. Andreoli, M. C. F. C. Felinto, O L. Malta and H. F. Brito, J. Lumin., 2016, 170, 364-368. B. Shao, P. Feng, X. Wang, F. Cui and X. Yang, J. Phys. Chem. C, 2019, 123, 7467-7474.

C. Vaysse, L. Guerlou-Demourgues, A. Demourgues, F. Lazartigues, D. Fertier and C. Delmas, J. Mater. Chem., 2002, 12, 1035-1043.

S. G. de Ávila, L. C. C. Silva and J. R. Matos, Microporous Mesoporous Mater., 2016, 234, 277-286.

B. Tian, X. Liu, C. Yu, F. Gao, Q. Luo, S. Xie, B. Tu and D. Zhao, Chem. Commun., 2002, 2, 1186-1187.

H. Joshi, D. Jalalpoor, C. Ochoa-Hernández, W. Schmidt and F. Schüth, Chem. Mater., 2018, 30, 8905-8914. A. F. Morais, F. O. Machado, A. C. Teixeira, I. G. N. Silva, E. Breynaert and D. Mustafa, J. Alloys Compd., 2019, 771, 578-583. A. A. S. Gonçalves, M. J. F. Costa, L. Zhang, F. Ciesielczyk and M. Jaroniec, Chem. Mater., 2018, 30, 436-446. E. R. Souza, I. G. N. Silva, E. E. S. Teotonio, M. C. F. C. Felinto and H. F. Brito, J. Lumin., 2010, 130, 283-291. C. C. Gheorghiu, B. F. Machado, C. Salinas-Martínez de Lecea, M. Gouygou, M. C. Román-Martínez and P. Serp, Dalt. Trans., 2014, 43, 7455-7463. H. Yang, P. X. Hou, S. Bai, M. Z. Wang and H. M. Cheng Chem. Phys. Lett., 2001, 345, 18-24.

B. Gržeta, D. Lützenkirchen-Hecht, M. Vrankić, S. Bosnar, A. Šarić, M. Takahashi, D. Petrov and M. Bišćan, Inorg. Chem., 2018, 57, 1744-1756.

59 J. Hölsa, T. Leskelä and M. Leskelä, Inorg. Chem., 1985, 24 
1539-1542.

60 S. Ida, Y. Sonoda, K. Ikeue and Y. Matsumoto, Chem. Commun., 2010, 46, 877-879.

61 K. Binnemans, Coord. Chem. Rev., 2015, 295, 1-45. F. A. Silva, H. A. Nascimento, D. K. S. Pereira, E. E. S. Teotonio, H. F. Brito, M. C. F. C. Felinto, J. G. P. Espínola, G. F. Sá and W. M. Faustino, J. Braz. Chem. Soc., 2013, 24, 601-608. D. Mustafa, I. G. N. Silva, S. R. Bajpe, J. A. Martens, C. E. A. Kirschhock, E. Breynaert and H. F. Brito, Dalt. Trans., 2014, 43, 13480-13484. I. G. N. Silva, A. F. Morais, H. F. Brito and D. Mustafa, Ceram. Int., 2018, 44, 15700-15705.
Santos and L. S. Gonçalves, Chem. Mater., 2005, 17, 58035809.

J. Zabicky, Ed., The Chemistry of Metal Enolates, Part 1, WILEY, West Sussex, England, 1st edn., 2009.

R. M. Supkowski and W. D. W. Horrocks, Inorganica Chim. Acta, 2002, 340, 44-48. W. DeW Horrocks Jr and D. R. Sudnick, Acc. Chem. Res, 1981, 14, 384-392.

M. Louer, D. Louer, A. Lopez Delgado and O. Garcia Martinez, Eur. J. Solid State Inorg. Chem., 1989, 26, 241253.

70

F. Geng, Y. Matsushita, R. Ma, H. Xin, M. Tanaka, F. Izumi, N. Iyi and T. Sasaki, J. Am. Chem. Soc., 2008, 130, 1634416350. 